\title{
Quality of albendazole tablets legally circulating in the pharmaceutical market of Addis Ababa, Ethiopia: physicochemical evaluation
}

\author{
Assegid Seifu', Elias Kebede ${ }^{1}$, Belachew Bacha ${ }^{2,3}$, Achenef Melaku $^{1 *}\left(\mathbb{D}\right.$ and Tadese Setegn ${ }^{2}$
}

\begin{abstract}
Background: Parasitic diseases are the main challenge of livestock production in the world. They are mainly controlled by the use of anthelmintic drugs. To be effective, the drugs should contain the appropriate amount of active pharmaceutical ingredient (API) and have the required physical characteristics. In this study, qualitative and quantitative assessments were performed to evaluate the quality of different brands of albendazole tablets legally circulating in pharmaceutical markets of Addis Ababa, Ethiopia.

Methods: Ultraviolet-Visible Spectroscopy (UVS), Fourier Transform Infrared Spectroscopy (FTIR) and HighPerformance Liquid Chromatography (HPLC) were used for identification. Quantitative analysis was performed by HPLC. United States Pharmacopeia standard was used as a control to evaluate the identity and content of the API in the samples. A total of 10 batches of albendazole tablets from six different brands were collected and evaluated.

Results: All brands of albendazole tablets, except one, had acceptable physical characteristics. There was gross contamination in one batch, weight variation in 4 (40\%) batches, and absence of package insert in 2 (20\%) batches. All three methods of evaluation (UVS, FTIR and HPLC) confirmed that all batches passed the identity test. Quantitative analysis showed that no batch had API above the acceptable limit. However, 30\% of batches from three different brands contained lower amount of API per tablet than the acceptable limit.

Conclusions: All batches of albendazole circulating in the market in Addis Ababa did not fulfil either physical or chemical quality standards. The most important finding of this research was the presence of drugs with lower level of API than the acceptable limit. This can lead to treatment failure and favour the emergence of parasites that are resistant to drugs. Therefore, there should be a thorough evaluation of drugs before approval. The study also revealed the importance of occasional assessment of drugs circulating even in the legal market.
\end{abstract}

Keywords: Albendazole, FTIR, HPLC, Quality assessment, UVS, Ethiopia

\section{Background}

Parasitic diseases are the main challenge of livestock production in the world. They cause huge losses by inducing high morbidity and mortality. Hence, livestock producers use anthelmintic drugs to control helminthic parasites. Several anthelmintic drugs are available in the market. Albendazole is the most commonly used

\footnotetext{
* Correspondence: tbeyene11@gmail.com

'Department of Veterinary Pharmacy, College of Veterinary Medicine and Animal Sciences, University of Gondar, P. O. box= 196, Gondar, Ethiopia Full list of author information is available at the end of the article
}

anthelmintic drug in Ethiopia [1-3]. It is used for the treatment of variety of parasitic worms due to its broad spectrums of activities [2]. To be effective in treating parasitic diseases, the drug should have the necessary physical and chemical qualities $[4,5]$.

Albendazole imported by private companies takes the largest share in Ethiopian market, in a limited extent the drug is also produced domestically. The quality of veterinary drugs imported, manufactured and distributed in the country is controlled by Ethiopian Veterinary Drug and Feed Control and Administration Authority. The

(c) The Author(s). 2019 Open Access This article is distributed under the terms of the Creative Commons Attribution 4.0 International License (http://creativecommons.org/licenses/by/4.0/), which permits unrestricted use, distribution, and 
authority has checkpoints at potential entry sites. However, there may be importation and distribution of substandard drugs $[3,6]$. There are also complaints from animal health professionals and animal owners regarding the effectiveness of available drugs in the market [2]. Many stakeholders in the animal health sector have concerns about treatment failures [7].

Studies in other part of the world showed the possibility of counterfeiting on both branded and generic products $[8,9]$. It has been reported that drugs on the market can have the correct ingredients, insufficient quantity of the active ingredient, wrong ingredients, no active ingredients or false or misleading packaging. They may also contain different quantities of impurities that can be harmless or toxic $[10,11]$.

Several studies have been conducted on the efficacy of albendazole using in vivo or in vitro techniques in Ethiopia and reported good or low efficacy [1, 3, 12]. The low efficacy reports may be related either to the development of drug resistance by parasites or the quality of the preparation. This necessitated further investigation and comparison with standard products. There was no attempt in the country so far to assess the quality of albendazole tablets legally circulating in the market. Therefore, this study was designed to evaluate the quality of different brands and batches of albendazole tablets sold in the legal pharmaceutical markets in Addis Ababa, Ethiopia.

\section{Methods}

This study was conducted from November, 2016 to April, 2017 in Addis Ababa city which is the capital city of Ethiopia. The city acts as a hub for distribution of veterinary pharmaceuticals in the country. All tests were conducted in the National Animal Products, Veterinary Drug and Feed Quality Assessment Centre. Ten batches of albendazole tablets from six different brands with three different labelled dose (strength) (300, 600 and $2500 \mathrm{mg}$ per tablet) of albendazole were collected randomly from different legal veterinary pharmacies in the city.

Samples were evaluated for various physical characteristics, packing information, label and information insert (leaflet), and weight. For weight evaluation, twenty tablets from each batch were weighed individually and compared [13].

For the identification test, FTIR, UVS and HPLC were used. In the FTIR approach, approximately $200 \mathrm{mg}$ of pure $\mathrm{KBr}$ crystal was taken and finely crushed by mortar and pestle. Then $2 \%$ of the powdered albendazole was added. The two powders were thoroughly mixed together and using oil pressure rotary pump a disk was formed. Another disk of $\mathrm{KBr}$ without albendazole was also prepared. Then both disks were placed on the sample handler and inserted into the instrument [13].

In the UVS spectrometric test, a portion of a clear solution of both sample and standard were taken separately. These solutions were diluted with acidified methanol to obtain solutions containing $10 \mu \mathrm{g}$ of albendazole per $\mathrm{mL}$. Then, the test and the standard solutions were examined spectrophotometrically over the spectral range from 200 to $400 \mathrm{~nm}$ [12].

HPLC equipped with an ultraviolet-visible detector (SPD-20A/20AV, Shimadzu Corporation, Japan) was used for qualitative and quantitative evaluation. HPLC grade solvents and albendazole $200 \mathrm{mg}$ standard (USP-CRM, USA) were used. In HPLC system, we used a $254 \mathrm{~nm}$ detection wave length and a $4.6 \mathrm{~mm} \times 25 \mathrm{~cm}$ column type that contains 5 pparticle sizes. According to USP [13], the flow rate was one $\mathrm{mL}$ per minute. The total chromatography run time was $12 \mathrm{~min}$. The mobile phase in HPLC machine was prepared by dissolving $0.5 \mathrm{~g}$ of monobasic ammonium phosphate in

Table 1 Physical characteristics of the tablets

\begin{tabular}{|c|c|c|c|c|c|c|}
\hline Product & $\begin{array}{l}\text { Label dose (strength) } \\
\text { of API (mg/tablet) }\end{array}$ & Uniformity of shape & Uniformity of size & Uniformity of colour & Breaks, cracks and splits & $\begin{array}{l}\text { Surface spot or } \\
\text { contamination }\end{array}$ \\
\hline \multirow[t]{2}{*}{ Brand 1} & 2500 & Yes & Yes & Yes & No & No \\
\hline & 300 & Yes & Yes & Yes & No & No \\
\hline Brand 2 & 2500 & Yes & Yes & Yes & No & No \\
\hline \multirow[t]{2}{*}{ Brand 3} & 2500 & Yes & Yes & Yes & No & No \\
\hline & 600 & Yes & Yes & Yes & No & $Y_{e s}^{a}$ \\
\hline Brand 4 & 600 & Yes & Yes & Yes & No & No \\
\hline \multirow[t]{2}{*}{ Brand 5} & 2500 & Yes & Yes & Yes & No & No \\
\hline & 300 & Yes & Yes & Yes & No & No \\
\hline \multirow[t]{2}{*}{ Brand 6} & 2500 & Yes & Yes & Yes & No & No \\
\hline & 300 & Yes & Yes & Yes & No & No \\
\hline
\end{tabular}

${ }^{a}$ A sample with gross contamination, API Active Pharmaceutical Ingredient 
Table 2 Packing information and label for the different brands

\begin{tabular}{|c|c|c|c|c|c|c|c|}
\hline Product & Container and closer & $\begin{array}{l}\text { Medicine strength } \\
\text { (mg/tablet) }\end{array}$ & Dosage statement & Batch/ Lot No & $\begin{array}{l}\text { Manufacture and } \\
\text { expiry date }\end{array}$ & Storage information & $\begin{array}{l}\text { Leaflet or package } \\
\text { insert }\end{array}$ \\
\hline \multirow[t]{2}{*}{ Brand 1} & Yes & Yes & Yes & Yes & Yes & Yes & Yes \\
\hline & Yes & Yes & Yes & Yes & Yes & Yes & Yes \\
\hline Brand 2 & Yes & Yes & Yes & Yes & Yes & Yes & Yes \\
\hline \multirow[t]{2}{*}{ Brand 3} & Yes & Yes & Yes & Yes & Yes & Yes & Yes \\
\hline & Yes & Yes & Yes & Yes & Yes & Yes & Yes \\
\hline Brand 4 & Yes & Yes & Yes & Yes & Yes & Yes & Yes \\
\hline \multirow[t]{2}{*}{ Brand 5} & Yes & Yes & Yes & Yes & Yes & Yes & $\mathrm{No}^{\mathrm{a}}$ \\
\hline & Yes & Yes & Yes & Yes & Yes & Yes & $\mathrm{No}^{\mathrm{a}}$ \\
\hline \multirow[t]{2}{*}{ Brand 6} & Yes & Yes & Yes & Yes & Yes & Yes & Yes \\
\hline & Yes & Yes & Yes & Yes & Yes & Yes & Yes \\
\hline
\end{tabular}

${ }^{\mathrm{a}}$ There was no leaflet or package insert

$400 \mathrm{~mL}$ of deionized HPLC grade water and $600 \mathrm{~mL}$ methanol. The sample was prepared by transferring $100 \mathrm{mg}$ of finely powdered tablets of albendazole into a $50 \mathrm{~mL}$ volumetric flask. Then, $5 \mathrm{~mL}$ of diluent was added, sonicated for $30 \mathrm{~min}$, diluted with methanol to volume, mixed thoroughly and filtered using Whatman filter paper. The first $15 \mathrm{~mL}$ of the filtrate was discarded and then $5 \mathrm{~mL}$ of the clear stock filtrate was transferred into the second volumetric flask and diluted with methanol to obtain a solution containing $200 \mu \mathrm{g}$ of albendazole per $\mathrm{mL}$ [13]. The standards were prepared based on the direction in USP [13]. Prepared solutions were passed through $0.45 \mu \mathrm{m}$ syringe filter and transferred into $1.5 \mathrm{~mL}$ HPLC vial. About $20 \mu \mathrm{L}$ of the standard and the sample were injected into the HPLC machine separately. The retention time of the peak for albendazole in the sample and the standard were compared for identification since the retention time of the peak for albendazole in the chromatogram of the sample corresponds to that of the standard preparation [13]. The peak area was used for quantification [4, 14]. All procedures were done at least three times to increase the precision. System stability was checked prior to running each sample.

\section{Data management and analysis}

The data were checked, coded, and entered into a Microsoft excel work sheet and descriptive statistics were used to summarize the data. The mean, standard deviation, and relative standard deviation (RSD) were used to compare the albendazole standard with different brands. The amount of albendazole in each brand or tablet was calculated by considering the peak area of the sample, the standard, dilution rate and the label claim [13]. According to USP, an albendazole tablet should contain $90-110 \%$ of the labelled amount for acceptable quality [13].

Table 3 Packing information, expiration date, and weight of different brands of albendazole

\begin{tabular}{|c|c|c|c|c|c|}
\hline Product & Label dose (strength) of API (mg/tablet) & Blisters $\times$ tablet & Expiration date & $\begin{array}{l}\text { Weight mg (mean } \pm \text { SD) } \\
(n=20)\end{array}$ & $\frac{\mathrm{RSD}}{2}$ \\
\hline \multirow[t]{2}{*}{ Brand 1} & 2500 & $55(11 \times 5)$ & 2018 & $5950 \pm 116.20$ & 1.95 \\
\hline & 300 & $60(10 \times 6)$ & 2019 & $1980 \pm 69.71$ & $3.52^{\mathrm{a}}$ \\
\hline Brand 2 & 2500 & $60(15 \times 4)$ & 2019 & $6080 \pm 55.75$ & 0.91 \\
\hline \multirow[t]{2}{*}{ Brand 3} & 2500 & $60(12 \times 5)$ & 2020 & $4900 \pm 201.53$ & $4.11^{\mathrm{a}}$ \\
\hline & 600 & $60(5 \times 12)$ & 2020 & $4980 \pm 43.02$ & 0.86 \\
\hline Brand 4 & 600 & $55(11 \times 5)$ & 2019 & $4880 \pm 60.12$ & 1.23 \\
\hline \multirow[t]{2}{*}{ Brand 5} & 2500 & $60(12 \times 5)$ & 2019 & $5870 \pm 56.88$ & 0.96 \\
\hline & 300 & $60(10 \times 6)$ & 2019 & $1810 \pm 36.63$ & $2.02^{\mathrm{a}}$ \\
\hline \multirow[t]{2}{*}{ Brand 6} & 2500 & $60(12 \times 5)$ & 2019 & $5730 \pm 123.19$ & $2.15^{\mathrm{a}}$ \\
\hline & 300 & $55(11 \times 5)$ & 2019 & $4830 \pm 89.35$ & 1.85 \\
\hline
\end{tabular}

${ }^{\mathrm{a}}$ Did not meet the specification for uniformity of weight, API Active Pharmaceutical Ingredient, SD standard deviation, RSD Relative Standard Deviation 
Table 4 Different strengths of the drug that passed the test requirement

\begin{tabular}{lll}
\hline Product & Label dose (strength) of API (mg/tablet) & Identity test \\
\hline Brand 1 & 2500 & Pass \\
& 300 & Pass \\
Brand 2 & 2500 & Pass \\
Brand 3 & 2500 & Pass \\
& 600 & Pass \\
Brand 4 & 600 & Pass \\
Brand 5 & 2500 & Pass \\
& 300 & Pass \\
Brand 6 & 2500 & Pass \\
& 300 & Pass \\
\hline
\end{tabular}

API Active Pharmaceutical Ingredient

\section{Results}

All brands of albendazole tablets had uniform shape, size and colour. There were no breakage and cracking of tablets in all brands. Gross contamination was observed in one batch (Table 1).

The packing information and labelling of the different albendazole brands were assessed based on WHO criteria [15]. Out of the 6 brands, one (16.7\%) brand or two $(20 \%)$ batches had no leaflet or package insert (Table 2).
The weight uniformity of albendazole tablets of each brand are presented in Table 3 . The study revealed that out of the ten batches, $4(40 \%)$ did not comply with the official pharmacopoeial specification limit [13].

Concerning the identification test, all three methods (UVS, FTIR and HPLC) confirmed that all brands passed the identity test, verifying that all samples had albendazole as an active pharmaceutical ingredient (API) in their formulations (Table 4, Figs. 1 and 2). Fig. 1 depicts that both the sample and the standard have maximum absorbance on the same or equivalent wave length which confirmed that the sample had the intended API. Figure 2 shows the chromatographs of the standard and sample at nearly the same retention time.

As it is indicated in Tables 5, $3(50 \%)$ brands and $3(30 \%)$ batches contained the amount of albendazole which was lower than the acceptable limit. However, the result indicated that there was no drug sample which contained above the acceptable limit.

\section{Discussion}

For successful therapeutic effect, a pharmaceutical product should contain the appropriate amount of active pharmaceutical ingredient (API) and required physical characteristics. The manufacturer should also provide appropriate information including the product name,
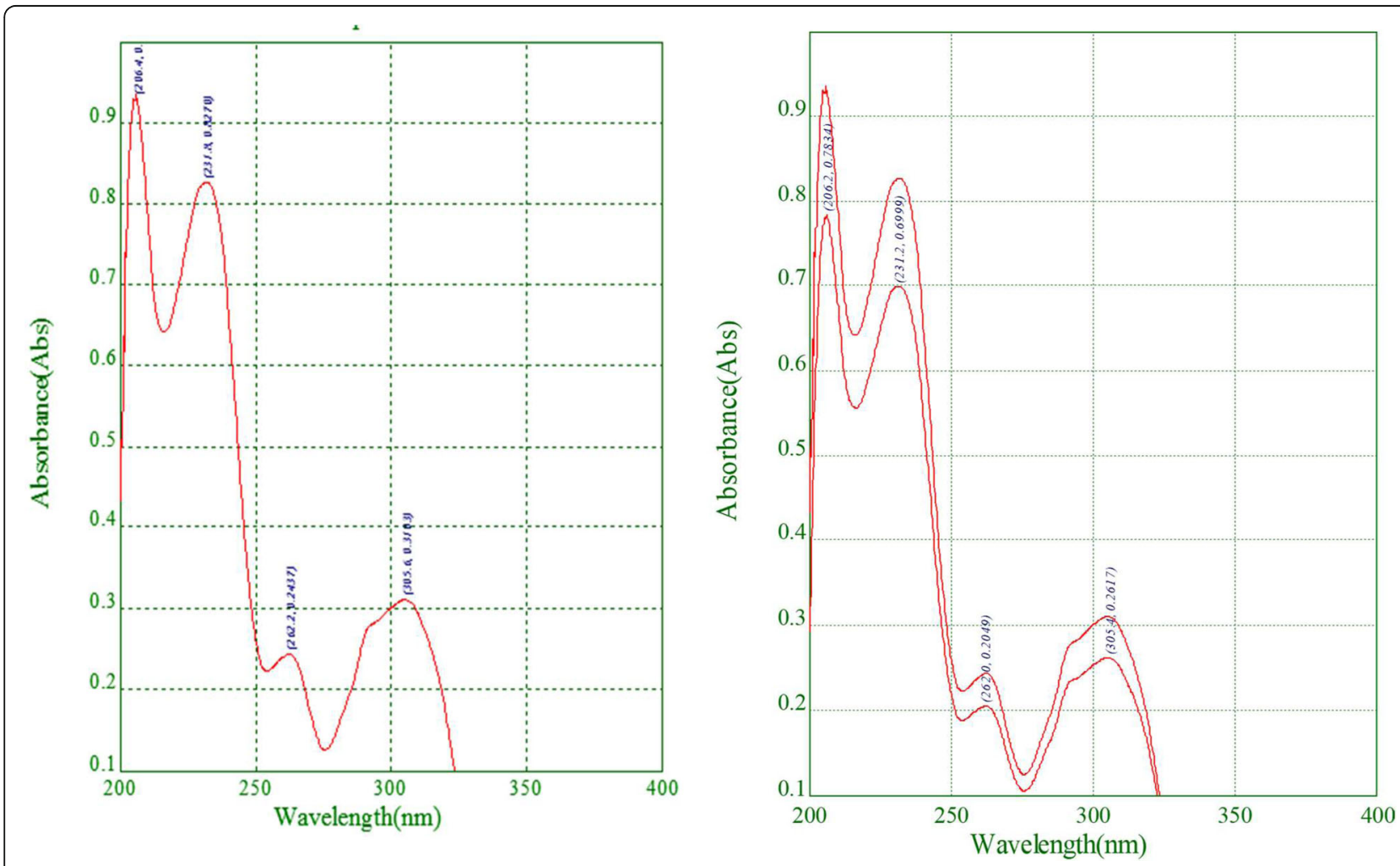

Fig. 1 Ultraviolet-visible spectra of Albendazole for primary identification test (left-side standard and right-side sample scans, being superimposed) 


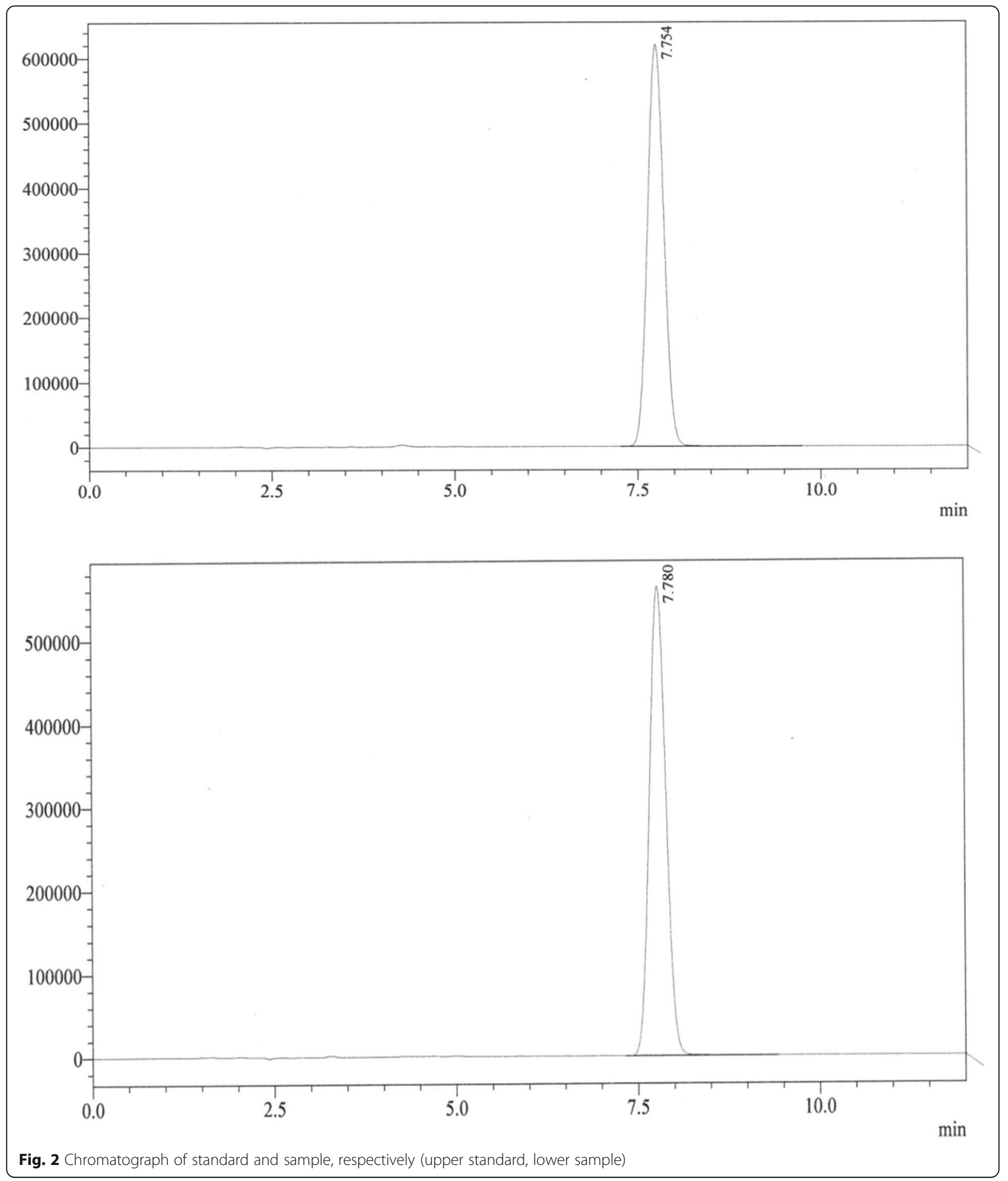

amount of API, the indications, contra-indications, warnings, storage information, expiration date, batch number, withdrawal periods, manufacturer name and address, and leaflet insert. In this study, problems were observed with labelling and physical characteristic by gross contamination in one batch and absence of leaflet in one brand (two batches).

Considering the weight per tablet for each brand or batch of a drug is important to assure uniformity of dosage of a drug [13]. Dosage uniformity helps to ensure a 
Table 5 Percentage (\%) and content of brands in mg

\begin{tabular}{|c|c|c|c|c|c|}
\hline Product & Label dose (strength) of API (mg/tablet) & Label claimed (\%) & Assay (\% mean $\pm \%$ SD) & RSD & $\begin{array}{l}\text { Assay test } \\
(90-110 \%)\end{array}$ \\
\hline \multirow[t]{2}{*}{ Brand 1} & 2500 & 100 & $94.97 \pm 2.57$ & 2.71 & Pass \\
\hline & 300 & 100 & $97.64 \pm 0.74$ & 0.76 & Pass \\
\hline Brand 2 & 2500 & 100 & $99.88 \pm 0.60$ & 0.60 & Pass \\
\hline \multirow[t]{2}{*}{ Brand 3} & 2500 & 100 & $105.85 \pm 9.82$ & 9.28 & Pass \\
\hline & 600 & 100 & $100.82 \pm 4.61$ & 4.57 & Pass \\
\hline Brand 4 & 600 & 100 & $87.22^{\mathrm{a}} \pm 1.57$ & 1.80 & Fail \\
\hline \multirow[t]{2}{*}{ Brand 5} & 2500 & 100 & $94.93 \pm 1.80$ & 1.90 & Pass \\
\hline & 300 & 100 & $86.92^{\mathrm{a}} \pm 1.28$ & 1.47 & Fail \\
\hline \multirow[t]{2}{*}{ Brand 6} & 2500 & 100 & $84.75^{\mathrm{a}} \pm 0.69$ & 0.82 & Fail \\
\hline & 300 & 100 & $105.73 \pm 0.99$ & 0.93 & Pass \\
\hline
\end{tabular}

aelow 90\% (the acceptable range is 90-110\%) [12]; SD Standard Deviation, RSD Relative Standard Deviation, API Active Pharmaceutical Ingredient

constant dose of drug between individual dosage forms. In this study, assessment of the weight uniformity revealed that four batches did not meet the criteria. In contrast to the finding of this study, absence of variation was reported by Othman [16] in Yemen. The difference may be related to the manufacturing practices.

According to the official monograph of the USP [13], the API of a drug should not be less than $90 \%$ and greater than $110 \%$ of the label claim. If the API of drug is within the acceptance range, the drug can produce the required therapeutic effects with limited side effects on the patient. If the drug contains higher than the expected amount, it may not be safe. On the other hand, if the drug has lower amount of API, it may not cure the animal and my favour the development of anthelmintic drug resistance. There are frequent reports that show resistance to common anthelmintic drugs especially in warm and humid parts of the world [17].

In this study, out of the ten batches, $3(30 \%)$ had less than $90 \%$ of the API. This confirmed the presence of sub-therapeutic doses of anthelmintic drugs in the legal market of the country. It is obvious that the occurrence of such a scenario might not cure the patient or favour the development of resistance $[18,19]$. The substandard products could originate from poor preparation techniques during formulation and subsequent manufacturing processes, incorrect weighing and mixing, or it may be intentional to reduce the cost of production [20]. A relatively high prevalence of poor quality of albendazole was also reported in a separate study by Suleman et al. [21] in Ethiopia. In Yemen, Othman [16] assessed the quality of seven brands of albendazole and found that only two brands fulfil the British Pharmacopeia quality control standards. The presence of counterfeit anthelminthic drugs was also reported by Khan et al. [8] in Cambodia.

Despite some controlling practices in Ethiopia, there are still practices of misuse and smuggling of anthelmintic drugs. In addition, no strategy is in use to preserve and maintain the efficacy of anthelmintic drugs or to delay and prevent the emergence of anthelmintic drug resistance [22]. The findings of this study raise an alarming concern with regards to suboptimal drugs circulating in the legal market. This can contribute towards several interrelated problems. The implications of these can be: (1) inability to achieve the therapeutic goal which compromises the welfare and productivity of the animals, (2) obligatory repetitive treatments which incur additional costs for the farmer and (3) as a long-term effect, it may increase the presence of resistant parasite population. All of the aforementioned consequences of sub-standard drugs circulating in the legal market may further aggravate the already existing anthelmintic resistance and poor efficacy scenarios reported from different parts of the country [2, 7]. The clinical significance of drug resistance is highly crucial in notorious parasites like $H$. contortus in which a massive infection can kill the host $[3,7,23]$.

\section{Conclusions}

There were variations in contents of samples of different brands of albendazole. This variation can have significant influence on the drug activity. The presence of low level of API below the official recommended limit often results in treatment failure and favours the development of parasites resistance to the specific anthelmintic drug. Therefore, there should be a strong pre-registration evaluation and regular monitoring of the quality of drugs circulating in the market.

\section{Additional files}

Additional file 1: Chromatogram of samples and the standard. (DOC 303 kb)

Additional file 2: UVVis readings of Albendazole Reference and sample. (DOCX $62 \mathrm{~kb})$ 


\section{Abbreviations}

API: Active Pharmaceutical Ingredient; FTIR: Fourier Transformed Infrared Spectroscopy; HPLC: High Performance Liquid Chromatography; RSD: Relative Standard Deviation; SD: Standard Deviation; USP: United States Pharmacopeia; UVS: Ultraviolet Visible Spectroscopy; WHO: World Health Organization

\section{Acknowledgements}

Authors would like to thank the technical staff working in National Animal Products, Veterinary Drugs and Feed Quality Assessment Centre for their technical supports. We would also like to thank the laboratory authorities for allowing us to use the instruments, reagents and standards in the laboratory for our investigation.

\section{Funding}

The research materials (standard, reagents and instruments) were generous gift or permission of National Animal Products, Veterinary Drugs and Feed Quality Assessment Centre. Hence, there was no direct fund allocated for the research activities. Drug samples (albendazole Tablets) were purchased voluntarily by Dr. Elias Kebede.

\section{Availability of data and materials}

All data generated or analysed during this study are included in this published article and its Additional files 1 and 2. Alternatively, the data can also be obtained from the corresponding author upon request.

\section{Authors contributions}

AS, AM and EK designed the study and verify the methodologies, AS performed the sample collection, AS and EK wrote the draft manuscript. AS, BB and TS performed the laboratory analysis and played a role in analysis of the data, AM prepared, and EK and BB revised final version of the manuscript. All authors have read and approved the final version of the manuscript.

\section{Ethics approval and consent to participate}

Not applicable.

\section{Consent for publication}

Not applicable.

\section{Competing interests}

Authors would like to declare that there is no competing of interest of any kind.

\section{Publisher's Note}

Springer Nature remains neutral with regard to jurisdictional claims in published maps and institutional affiliations.

\section{Author details}

'Department of Veterinary Pharmacy, College of Veterinary Medicine and Animal Sciences, University of Gondar, P. O. box=196, Gondar, Ethiopia. ${ }^{2}$ Animal Products, Veterinary Drug and Feed Quality Assessment Centre, Veterinary Drug and Feed Control and Administration Authority, Addis Ababa, Ethiopia. ${ }^{3}$ Department of Food Hygiene and Technology, Faculty of Veterinary Medicine, Near East University, Nicosia, Cyprus.

\section{Received: 17 April 2018 Accepted: 10 April 2019}

Published online: 25 April 2019

\section{References}

1. Seyoum Z, Demessie Y, Bogale B, Melaku A. Field evaluation of the efficacy of common anthelmintics used in the control of gastrointestinal nematodes of sheep in Dabat district, Northwest Ethiopia. Ir Vet J. 2017;70(18):1-8. https://doi.org/10.1186/s13620-017-0097-6.

2. Wakayo BU, Dewo TF. Anthelmintic resistance of gastrointestinal parasites in small ruminants: a review of the case of Ethiopia. Vet Sci Technol. 2015;10: 1-4. https://doi.org/10.4172/2157-7579.S10-001.

3. Kumsa B, Wossene A. Efficacy of albendazole and tetramisole anthelmintics against Haemonchus contortus in experimentally infected lambs. Int J Appl Res Vet Med. 2006;4(2):94-9. http://www.jarvm.com/articles/Vol4lss2/Kumsa. pdf.

4. Belew S, Getachew M, Suleman S, Mohammed T, Deti H, D'Hondt M, et al. Assessment of efficacy and quality of two albendazole brands commonly used against soil-transmitted helminth infections in Jimma town, Ethiopia. PLoS Negl Trop Dis. 2015;9(9):1-15. https://doi.org/10.1371/journal.pntd.0004057.

5. Guetchueng ST, Nnanga EN. Quality control evaluation of brands of mebendazole $100 \mathrm{mg}$ tablets on the illegitimate pharmacy outlets. Int J Pharm Pharm Sci. 2014;6(8):355-7. https://innovareacademics.in/journals/ index.php/ijpps/article/view/1426/10252.

6. Sheferaw D, Getachew D, Bekele J, Denbarga Y. Assessment of anthelmintic resistance in gastrointestinal nematodes of small ruminants, dale district, southern Ethiopia. J Vet Med. 2013;5(9):257-61. https://doi.org/10.5897/JVMAH13.0215.

7. Eguale T, Chaka H, Gizaw D. Efficacy of albendazole against nematode parasites isolated from a goat farm in Ethiopia: relationship between dose and efficacy in goats. Trop Anim Health Prod. 2009;41:1267-73. https://doi. org/10.1007/s11250-009-9311-1.

8. Khan MH, Okumura J, Sovannarith T, Nivanna N, Akazawa M. Prevalence of counterfeit anthelminthic medicines : a cross-sectional survey in Cambodia. Trop Med Int Heal. 2010;15(5):639-44. https://doi.org/10.1111/j.1365-3156.2010.02494.x.

9. Newton PN, Green MD, Fernandez FM. Impact of poor-quality medicines in the 'developing' world. Trends Pharm Sc. 2010;31(3):99-101. https://doi.org/ 10.1016/j.tips.2009.11.005.

10. WHO, World Health Organization: Substandard and falsified medical products," 2018. Available at: http://www.who.int/en/news-room/fact-sheets/detail/ substandard-and-falsified-medical-products. Accessed 19 Mar 2017.

11. FIP, International Pharmaceutical Federation: FIP combats falsified and substandard medicines. Available at: https://www.fip.org/counterfeit medicines. Accessed 15 Jan 2017

12. Ahmed J, Duguma A, Regassa D, Belina D, Jilo R. Gastrointestinal nematode parasites of small ruminants and anthelmintics efficacy test in sheep of Haramaya district, eastern Ethiopia. Anim Vet Sci. 2017;5(3):39-44. https:// doi.org/10.11648/j.avs.20170503.11.

13. USP, United state pharmacopeia (USP): National formulary USP official Monograph, USP 35. Available at: http://www.drugfuture.com/ Pharmacopoeia/usp35/PDF/2082-2083\%20Albendazole\%20Tablets.pdf. Accessed 20 Oct 2016

14. van Tonder EC, de Villiers MM, Handford JS, Malan CE. Simple, robust and accurate high-performance liquid chromatography method for the analysis of several anthelmintics in veterinary formulations. J Chromatogr A. 1996; 729:267-72.

15. WHO. World Health Organization, Pharmacopoeial standards: ensuring the efficacy of a deworming medicine: albendazole chewable tablets. WHO Drug Information. 2015;29(4):440-5. http://apps.who.int/medicinedocs/ documents/s22209en/s22209en.pdf.

16. Othman GQ. Quality assessment of seven brands of albendazole tablets marketed in Yemen. Yemeni J Med Sci. 2017;11:46-52. https://doi.org/10. 20428/YJMS.11.1.A7.

17. Geerts S, Gryseels B. Drug resistance in human helminths: current situation and lessons from livestock. Clin Microbiol Rev. 2000;13(2):207-22. http://cmr. asm.org/content/13/2/207.full.pdf.

18. Adediran OA, Uwalaka EC. Effectiveness evaluation of levamisole, albendazole, ivermectin and Vernonia amygdalina in west African dwarf goats. J Parasitol Res. 2015;2015:1-5. https://doi.org/10.1155/2015/70682.

19. Shalaby HA. Anthelmintics resistance; how to overcome it? Iran J Parasitol. 2013;8(1):18-32. http://ijpa.tums.ac.ir/index.php/ijpa/article/view/530.

20. IMNA, Countering the Problem of Falsified and Substandard Drugs. 2013 [Online]. Available: https://www.nap.edu/resource/18272/ CounteringtheProblemofFalsifiedandSubstandardDrugs_RB.pdf. Accessed 20 Jan 2018

21. Suleman S, Zeleke G, Deti H, Mekonnen Z, Duchateau L. Quality of medicines commonly used in the treatment of soil transmitted helminths and giardia in Ethiopia: a nationwide survey. PLoS Negl Trop Dis. 2014;8(12): e3345. https://doi.org/10.1371/journal.pntd.0003345.

22. Kumsa B, Tolera A, Nurfeta A. Comparative efficacy of seven brands of albendazole against naturally acquired gastrointestinal nematodes in sheep in Hawassa,Southern Ethiopia. Turk J Vet Anim Sci. 2010;34(5):417-25. https://doi.org/10.3906/vet-0712-28.

23. Roos MH. Drug resistance in the sheep nematode parasite Haemonchus contortus, mechanisms and clinical perspectives. In: Mayers DL, editor. Antimicrobial drug resistance. Infectious disease: Humana Press; 2009. p. $1127-32$ 